\title{
Internet Thinking for Omnimedia Reconstruction of News Production and Dissemination Mechanism of Chinese Traditional Mass Media
}

\author{
Shaoshuo Cai ${ }^{*}$, Fen Xie ${ }^{2}$ \\ ${ }^{1}$ School of Literature and Journalism, South-Central University for Nationalities, Wuhan, Hubei Province, China. \\ E-mail: css94223@126.com \\ ${ }^{2}$ School of Communication, Shenzhen University, Shenzhen, Guangdong Province, China.
}

\begin{abstract}
This paper briefly combs the practical innovation of Chinese traditional media in news production and dissemination mechanism, focuses on the on the analysis of subjective and objective factors that restrict the innovation and reform of its original mechanism, and puts forward the reconstruction and innovation mechanism of news production and dissemination in the omnimedia era with the thinking of the Internet. Set up service thinking, set up an all-round agenda, report major social events in the whole process to build a dynamic media platform; Set up the user's thinking, carry out all-round mass communication, meet the audience's personalized news consumption needs in all aspects to build a multi-dimensional platform; Set up open thinking, conduct audience interaction in all directions, strengthen the public participation experience in the whole process to build a multi-terminal communication platform; Set up platform thinking, expand the communication effect in all directions, give full play to the efficiency of media integration in all aspects to provide the multi-form experience.
\end{abstract}

Keywords: Internet Thinking; Omnimedia Reconstruction; News Production and Dissemination; The Omnimedia

Newspapers, radio, television and other traditional media have all written a great deal in time river with their greatest influence in the long media development history. At the same time, the news production and dissemination mechanism of traditional media represented by them has also played an important role in the civilization and development of the human information society. However, in the omnimedia era with the rapid development of new media, various communication media such as text, pictures, audio and long and short videos are combined by the technical means of the Internet, making the mechanism of news production and dissemination of traditional media unable to meet the needs of economic and social development. Therefore, how to carry out thinking innovation and mechanism reconstruction under the background of convenient and multifarious omnimedia has become a reform proposition that the traditional media, which is at the critical point of transformation and upgrading, urgently needs to answer. The Chinese government has put forward the omnimedia development strategy of building dynamic, multi-dimensional media and therefor to provide multi-terminal communication and multi-form experience to deepen the reform of China's media industry, which provides ideas for how Chinese traditional mass media change the paradigm of news production and dissemination in the omnimedia $\operatorname{era}^{[1]}$.

\section{Omnimedia innovation of news production and dissemination for the traditional mass media}

Copyright (C) 2020 Shaoshuo Cai et al.

doi: $10.18686 /$ mcs.v2i1.1296

This is an open-access article distributed under the terms of the Creative Commons Attribution Non-Commercial License

(http://creativecommons.org/licenses/by-nc/4.0/), which permits unrestricted non-commercial use, distribution, and reproduction in any medium, provided the original work is properly cited. 
The omnimedia is the development direction proposed by the Chinese government for the problems existing in traditional mass media in practice. It is quite realistic, thoughtful and innovative. A dynamic media refers not only to the media's reporting and continuous display of news events of public concern, but also to the whole process of news media's operation, which organically connects the production and dissemination links such as news planning, writing, editing, distribution and feedback, and jointly weaves an information dissemination highway supported by the Internet "circuit". The practice and innovation of the dynamic media in the newspaper industry has led to the emergence of omnimedia news center model. Yantai Daily Media Group established an omnimedia news center in 2008 by merging the interview departments of the three major newspapers to form a news agency within the group, which completely changed the way the traditional newspaper industry conducts individual operations. At the same time, this "central kitchen" type of integration of group operations has also completely subverted the news dissemination mode. For example, Guangzhou Daily established a mobile news department in June 2007 to create a cooperation platform for both paper and new media version. Through intensive production of news content, the "high dissemination effect and low production cost" in the multi-layer distribution of information can be realized. At present, many newspapers across the country such as Sanxiang Huasheng, Henan Elephant Financial Media and People's Daily have also adopted the "central kitchen" model. This model has already formed a basic consensus of "integration of the old and the new, one collection, multiple generation and multiple distribution" in practice, and is also the development trend of newspapers embracing new media with the help of the Internet.

A multi-dimensional media refers to news be presented by a multi-dimensional and multi-lateral way in the form of text, pictures, sound, pictures, animation, and charts et al., so that the media become a multi-functional information carrier. This multi-dimensional presentation of media has also expanded Canadian propagandist McLuhan's theory of "media is the extension of human beings" and reached the state of communication where everything is media and all people are media. The practice and innovation of "multi-dimensional media" in the TV industry has resulted in the interactive mode of "the station as the center and the network as the auxiliary": TV station completes the online programs, the network completes the online version of the programs and the online actions. China Central Television (CCTV) opened China network television's CNTV in 2009. After 10 years of development and in combination with the changes and developments in the needs of Internet users, it has completed the transformation from a "network version of CCTV" to a "domestic mainstream video news website" for multiple end users such as computers, mobile phones and televisions, and is able to provide rich content and various forms of audio-visual services. This integration of network resources enables TV resources to be fully and reasonably used in a composite way, realizing seamless docking of user needs and maximizing the benefits of communication.

A multi-terminal communication media mainly refers to all the audiences participating in the production and dissemination of news consciously, working together and innovating together to become media operators and participants in news dissemination. This media situation of "everyone is a journalist and everyone has a microphone" has completely changed the production and dissemination mechanism in which news is monopolized by professional journalists and editors with press cards. "Multi-terminal communication media" has created a "PUGC" content production mode in the broadcasting industry: in the mobile audio industry, traditional radio hosts, voice players and professional users such as self-media KOL produce and produce content and establish clear copyright cooperation mode with mobile stations. For example, Himalayan FM helped the anchor on the platform realize micro-entrepreneurship and jointly created 20 million audio and content in the platform.

Media that provides multi-form experience means that the media's news production efficiency has reached the maximum saturation, the communication mechanism efficiency has reached the maximum enhancement, and the audience's saturation and satisfaction of receiving information have reached the limit. In the broadcasting industry, new modes such as "live broadcast through media", "audio reading" and "cross-screen interaction" and "triple web integration" in the television industry can all rely on new technologies such as big data, cloud computing and artificial intelligence to create feasibility for the media to understand unknown users in the past, implement a strategy of focusing 
and accurate media to meet the needs of users, and implement the arrival rate, a real communication effect evaluation index.

\section{Constraints on the production and dissemination mechanism of traditional media news in the omnimedia era}

Canadian communication scholar Paul Levinson put forward a theory of contemporary media. There are three levels: old media, new media and new NEW media. Traditional mass media such as newspapers, radio and television are the representatives of the old media era. In the new NEW media era supported by artificial intelligence, virtual reality and other technologies, the disadvantages of omnimedia communication of traditional news production and communication mechanism are gradually exposed due to the inability to break through the limitations of media technology and communication form.

2.1 The one-way separation process of editing and distribution of traditional mass media results in the waste of news production factors. Under the media operation mechanism of administrative division, the progress of news production and dissemination is designed and arranged according to the respectively characteristic of each media. Whether it is newspapers, radio or television, they generally follow the three links of news gathering, editing and distribution to carry out and operate. There is only inheritance relation and no mutual relation between each link. Not only is there no reaction between each link, only passive cooperation and no interactive feedback. This kind of link does not meet the requirements of overall planning and integration for the optimization of news resources under omnimedia production, resulting in serious waste of news production factors, which makes it difficult to ensure the continuous output of high-quality news and the improvement of the core competitiveness of news media.

2.2 Secondly, due to the relatively backward concept of news dissemination and rigid mode of thinking, or due to the pressure of administrative intervention and other reasons, the traditional mass media lack coverage of complex and sensitive social issues, or even do not record and report the news, or even their reports are superficial, careless and perfunctory. Since China is undergoing a drastic transformation period, there exists uncountable sensitive issues concerning the national economy and people's livelihood. In terms of another meaning of dynamic media, the more sensitive social events are which people concern, the more attention news media should pay to carry out all-round, basin-wide, and whole-process follow-up continuous reports from the occurrence, development to the end of news events. However, the traditional mass media lack such reports, which easily leads to the phenomenon of "bad money driving out good money" in journalism. For a long time, the traditional mass media intentionally or unintentionally avoid or selectively report some important issues. As a result, gradually the traditional mass media will be neglected and marginalized by the audience and their power of communication, guidance, influence and credibility will be put under severe challenge.

2.3 Traditional mass media is basically a single media form which often appeals to one or two senses of audience. Newspapers appeal to the vision of readers, radio appeals to the hearing of audience, and television appeals to the vision and hearing of audience. Moreover, the "line" reporter system is not conducive to the "first time" allocation of resources and pooling of materials to seize the commanding heights of public opinion in the campaign coverage of major social news. In the era of omnimedia, the audience's sensory functions are diverse. New media such as the Internet, mobile phones and wearable media appeal to users' sense of touch and even their sense of perception on the basis of audio-visual perception, thus further widening and extending the human body's sensory functions. News narration in the era of omnimedia requires the omniscient narration perspective of French literary theorist Zvetan Todorov to break through the limitation of time and space to spread in multi-dimensional, multi-elemental and multi-level ways, at last providing audiences with a cognitive picture to truly achieve a transcendent state of omnipotence.

2.4 Traditional mass media whose circulation and viewership ratings have generally declined are "out of touch" with audience. The audience's staying away from traditional media means that there is a gap and rift between the audience and the media, which indirectly proves the waste and losses of news production and communication resources, 
and also proves that the communication effect of traditional media is out of order and ineffective, and the coupling communication mechanism has gone wrong. The theory of "use and satisfaction" put forward by the communication scholar E. Katz holds that "the audience group restricts the process of media communication through active use of media" and points out that "the use of media is entirely based on individual needs and wishes". Then communication that does not pay attention to the effect of communication naturally is aimless, blind and ineffective, which is a waste of news production costs and communication resources.

\section{Internet thinking reconstruction of traditional mass media in news production and dissemination mechanism}

With the emergence of new media and the gradual deconstruction of traditional media in the new era of the Internet, the news production and dissemination mechanism of traditional mass media have obviously failed to meet the needs of the development of omnimedia. Schumpeter put forward the modern innovation theory in which he held that innovation originates from destructive creation process ${ }^{[4]}$, and in the new era of "great interconnection" under continuous development, traditional mass media must adhere to the path of transformation and integration development to reconstruct a brand-new news production and dissemination mechanism. In particular, it is necessary to redesign their own goals and value orientation under the framework of the "Four All Media" to search for their own media market space. Also, it's necessary to face the challenges of organizational structure and talents management in carrying forward the innate advantages, and integrate Internet thinking to innovate and construct the news production and communication mechanism in the omnimdia era, so as to reshape the public opinion ecology, media structure and communication methods.

3.1 Traditional mass media should set up service thinking, carry out all-round agenda setting, report major social events in the whole process, and construct "Dynamic Media". "The Spiral Effect of Silence" is increasingly strengthened in the omnimedia era. Any single event may become a social hot spot and sensitive news issue, which will further arouse the high attention of audience. In this kind of attention, the expression of opinions and the spiral spread of "silence" are highly accelerated. The traditional mass media should set up service thinking, meet the needs of the audience to obtain all kinds of news events anytime and anywhere, fully develop new media, actively set up agendas for major, hot and sensitive social hot events that meet the needs of users on all kinds of communication channels, participate in the whole process, and report in an interventionist way ${ }^{[5]}$. For example, in response to the public opinion fermentation on the fault of the female driver in a river-fall incident occurred in Chongqing, China, traditional mass media can not only seek the authoritative information of the bridge monitoring video released by the police, but also seek the truth restoration of the vehicle traveling data recorder through new media.

3.2 Traditional mass media should establish the users' thinking, carry out all-round mass communication, meet the audience's personalized news consumption needs in all aspects, and construct "Multi-dimensional Media". For example, the Beijing People's Broadcasting Station split seven specialized stations from a hodgepodge to operate independently and singly, and adjusted the category composition of specialized stations according to the requirements and wishes of audience, guided by the theory of Mass Communication and relying on the needs of audience, thus fully meeting the personalized information needs of audience. From early sensor news, robot writing to virtual/augmented reality technology (VR / AR), and then further to omnimedia (AI) precision push and block chain technology, a flood of new technologies present a social mirror image and a media landscape of "Multi-dimensional Media". Thus traditional mass media also need to adapt to the all-round transformation from content production to dissemination brought by new technologies.

3.3 Traditional mass media should be open-minded, conduct interaction with audience in all directions, strengthen the public participation experience in the whole process, and construct "Multi-terminal Communication Media". The essence of Internet spirit is openness, only on the basis of which, can there be practical innovations involving multiple subjects in news production and dissemination. For example, Internet users in Western European countries use the 
simple and convenient video production windows provided by social platforms such as "Picture Wall Report" and "Burn After Reading" to capture news events for news information gathering and writing and news products' uploading. This kind of social technology breaks through the "partition" between predecessors and recipients, integrates their identities, and provides direction and ideas for the construction of multi-terminal communication media in China at the team level.

3.4 Traditional mass media should set up platform thinking, expand communication effect in all aspects, fully leverage the effectiveness of media integration, and construct "Multi-form Experience Media". From the perspective of media integration in various parts of China, it focuses on creating three new media products, namely, content products, relationship products and service products. Traditional mass media establish platform thinking to conduct news production, which also means that media personnel should shift from work creation thinking to product manufacturing thinking. Through opening up platforms, media resources should be activated to fully achieve maximum audience contact and gain market access in terms of circulation, listening rate, audience rating and click rate.

\section{Conclusion}

To sum up, traditional mass media have made for an innovative way of news production and dissemination mechanism under the framework of "the omnimedia", but there are still some limitations such as single perspective and one-way editing process. Therefore, in the omnimedia era of news producing process regeneration and news dissemination subjects diversification, traditional mass media firstly are expected to overcome the shortage of omnimedia information producing capacity and producing methods of editorial staff, including those in leadership. Secondly, to redesign their business model and value orientation of news production under the framework of "the omnimedia" to find the media market space for their news products. Finally, it's necessary to realize the thinking innovation of journalists. Journalists of traditional mass media should continuously innovate and learn the Internet thinking while sharpening their practical ability. In the meantime, they are supposed to continuously interact with audience to produce high-quality news information content in various media forms and terminals under the situation of more professional, detailed and diverse news production and dissemination.

\section{References}

1. Shen ZF. Reconstruction of news production and dissemination mechanism under the framework of omnimedia.(in Chinese). Modern Communication (Journal of Communication University of China) 2019; (03). doi: 10.3969/j.issn.1007-8770.2019.03.003.

2. Nie DM. Analysis of the internet public opinion field and its research (in Chinese). Jiangxi Social Sciences 2013; (2).

3. Guo QG. Communication course (the 2nd Edition) (in Chinese). Beijing: China Renmin University Press; 2011. p. 167-168.

4. Joseph S. The theory of economic development. He W (translator). Beijing: Commercial Press; 1990. p. 73-81.

5. Yao LY. Innovation of news production concept based on "central kitchen" mode (in Chinese). Press Circles 2015; (14):63-67. doi:10.15897/j.cnki.cn51-1046/g2.2015.14.011. 